\title{
Nonlinear numerical analysis of SRC-RC transfer columns based on OpenSEES
}

\author{
Hao $\mathrm{Gu}^{1} \mathrm{a}^{*} \quad$ Yun ZOU ${ }^{1} \quad$ Ming Chen ${ }^{1}$ \\ 1:School of Environment Civil Engineering, Jiangnan University, Wuxi Jiangsu 214122, China; \\ aemail:937646196@qq.com \\ ${ }^{* *}$ Corresponding author:zouyun_22@126.com
}

\begin{abstract}
Keywords: steel reinforced concrete; transfer column; fiber model; finite-element analysis
Abstract. In order to study the seismic behavior of SRC-RC transfer column under low-cycle loading, the open source finite element software OpenSEES was used to establish models of SRC-RC transfer column based on fiber model and conduct numerical analysis. Compared with experimental results, numerical analysis results are found to be reasonable and valid. Then the influence of factors such as stirrup ratio and axial-load ratio are contrastively analyzed. The results show that axial-load ratio has a greater influence on the bearing capacity and hysteretic performance of the structure, but the stirrup ratio has less influence.
\end{abstract}

\section{Introduction}

The steel reinforced concrete (SRC) structure has been gradually applied in high-rise buildings and seismic region, because it has the high bearing capacity, good rigidity and hysteretic performance. The SRC-RC transfer column whose bottom floor use steel reinforced concrete and upper floor use reinforced concrete is special conversion structure form. The SRC-RC transfer column makes full use of the excellent properties of SRC column and don't increase the construction cost at the same time. It helps to realize the unity of economic indicators and safety performance.

In order to realize the reasonable over the bearing capacity and rigidity of upper and lower layer in SRC-RC vertical hybrid structure, SRC-RC transfer column can be set up to contact the lower SRC column and the upper RC column. At present, some domestic and foreign scholars have studied the bearing capacity and seismic behavior of the SRC-RC transfer column such as Xi'an University of Architecture and Technology Kai Wu [3] and other completed test. There are also some scholars using the finite element software such as ABAQUS [4] for numerical analysis of SRC-RC, but the use of open source finite element analysis software OpenSEES has not been reported. This paper uses the fiber model of the open source finite element analysis software OpenSEES to conduct numerical analysis on the SRC-RC transfer column.

\section{Finite Element Analysis Model}

\section{The basic information about the model}

To verity the rationality and validity of the finite element analysis, experiment done by Kai $\mathrm{Wu}$ [3] from Xi'an University Of Architecture And Technology is picked as the basis for modeling and simulation. Experimental parts use Q235 section steel, HRB335 longitudinal reinforcement, HPB235 stirrup. Specimen size and reinforcement section are shown in Fig 1 and reinforcement ratio is 2.28\%. Steel section are I10 and I14 beams, steel ratio is $4.08 \%$ and $6.11 \%$, axial compression ratio is 0.2 and the measured mechanical properties of steel see table 1.

In this paper, Etabs software is used to model (shown in Fig 2), and then model is transformed to OpenSEES code by Dr. Chen Xuewei [5] ETO software, and code is modified finally.

\section{Concrete constitutive model}

The concrete constitutive model uses Kent-Scott-Park[6] model in OpenSEES program, which by modifying the skeleton curves of concrete compressive peak stress, strain and softening slope to consider the influence of the lateral stirrups constraint, as shown in Fig 3. 


\section{Steel constitutive model}

As is shown in Fig 4, steel bar of this paper uses Giuffr-Menegotto-Pinto reinforcement constitutive relation which is Steel02 Material in OpenSEES. Its' skeleton is bilinear and reflects Bauschinger effect of the reinforcement.

\section{Calculation results and analyses}

The load displacement curves of two specimens which are established finite element model by OpenSEES under monotonic load are compared with the load-displacement curve plotted with the experimental data and shown in Fig.5. By comparison, the calculated results are close to the experimental results.

\section{Parameters analysis}

\section{Steel ratio}

A set of SRC-RC transfer columns based on experimental parts is designed with three different steel ratio and its' parameters are shown in table 2. Hysteresis curves and skeleton curves of three specimens in the axial pressure ratio 0.3 under cyclic loading are obtained through the finite element analysis and shown in Fig.6. It can be seen from the figure that with the increase of steel ratio, the ultimate load capacity of the specimen is improved, but the increase is not obvious. In addition, the hysteretic curve of the specimens after changing the steel ratio did not change significantly, indicating that the strength and seismic performance of the SRC-RC converter can't be improved.

\section{Axial pressure ratio}

In order to investigate the influence of axial compression ratio on the mechanical properties of the SRC-RC transfer column, taking two specimens whose steel ratio is $4.08 \%$ and $6.11 \%$ under low cyclic loading in axial compression ratio of $0.2,0.3$ and 0.4 of the pressure to conduct numerical analysis. The maximum hysteresis loops and skeleton curves can be obtained under different axial compression ratio and shown in Fig.7 and Fig.8. It can be seen from the figure, the axial compression ratio is different and the maximum hysteresis loops are also different. With the increase of the axial pressure ratio, the bearing capacity of the specimen is significantly increased.

\section{Comparison between SRC-RC and RC columns}

Taking the steel ratio for $4.08 \%$ of the specimen and establishing the SRC-RC-8 transfer column and $\mathrm{RC}-1$ column under low cyclic loading in axial compression ratio of 0.2 of the pressure conduct numerical analysis. The maximum hysteresis loops can be obtained and shown in Fig.9. As can be seen from the figure, the carrying capacity of SRC-RC transfer column was significantly higher than RC column.

\section{Tables.}

Table1: The measured mechanical properties of steel

\begin{tabular}{llccc}
\hline Type of steel & Type & $\begin{array}{c}\text { Yield Strength } \\
{[\text { [fy /MPa] }}\end{array}$ & $\begin{array}{c}\text { Ultimate strength } \\
{[\mathrm{fu} / \mathrm{MPa}]}\end{array}$ & $\begin{array}{c}\text { Elastic Modulus } \\
{[\text { Es } / \mathrm{GPa}]}\end{array}$ \\
\hline Reinforced & $\Phi 6$ & 364.3 & 461.5 & 201.0 \\
& $\Phi 16$ & 376.0 & 547.4 & 191.0 \\
\hline \multirow{5}{*}{ Section steel } & I14 Flange & 258.5 & 408.1 & 190.0 \\
& I14 Web & 300.4 & 432.7 & 203.0 \\
& I10 Flange & 267.6 & 428.1 & 185.0 \\
& I10 Web & 281.0 & 417.7 & 195.0 \\
\hline
\end{tabular}

Tabel2 : Model steel ratio parameter

\begin{tabular}{llll}
\hline Speciman number & SRC-RC-3 & SRC-RC-4 & SRC-RC-5 \\
\hline Steel type & I10 & I14 & I16 \\
\hline Steel ratio & $4.08 \%$ & $6.11 \%$ & $7.41 \%$ \\
\hline
\end{tabular}




\section{Figure.}

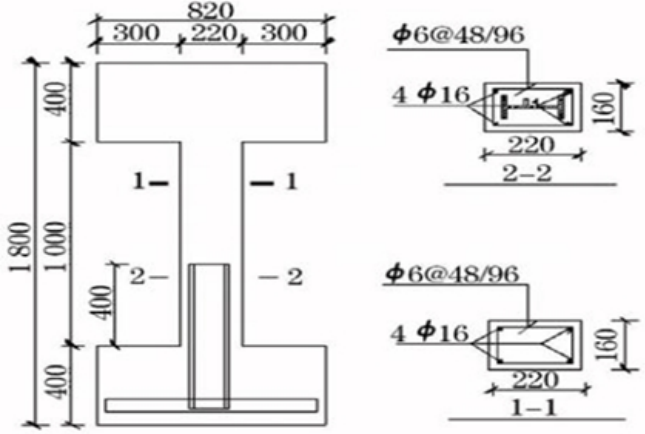

Fig 1. Specimen size and reinforcement section



Fig.3. Concrete constitutive

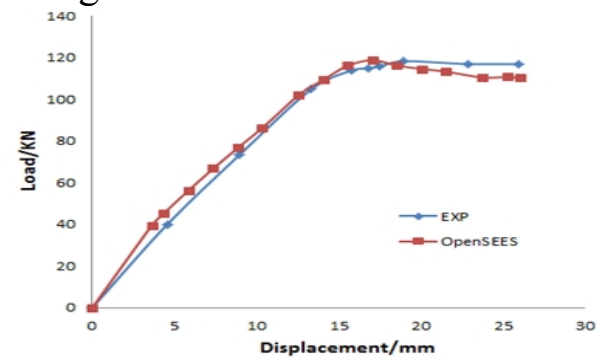

Specimen SRC-RC-1

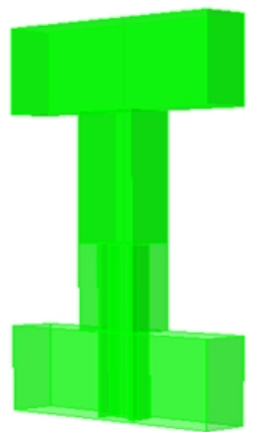

Fig 2. Finite element model

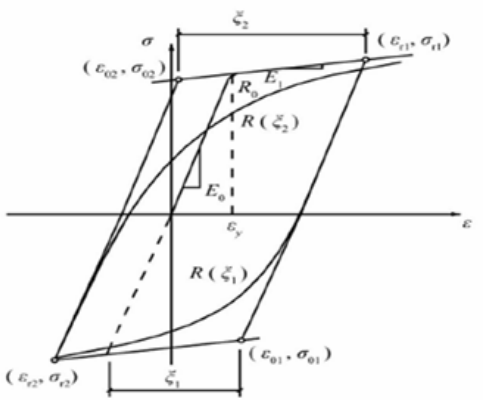

Fig 4. Steel constitutive

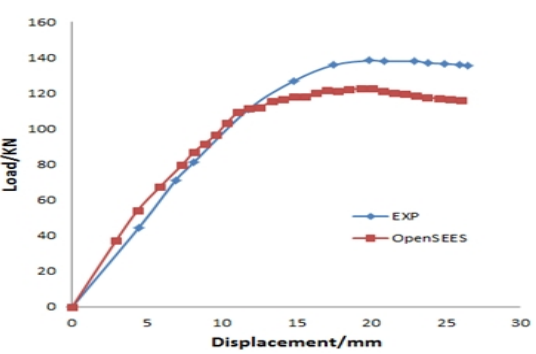

Specimen SRC-RC-2

Fig.5. Load-displacement curves comparison
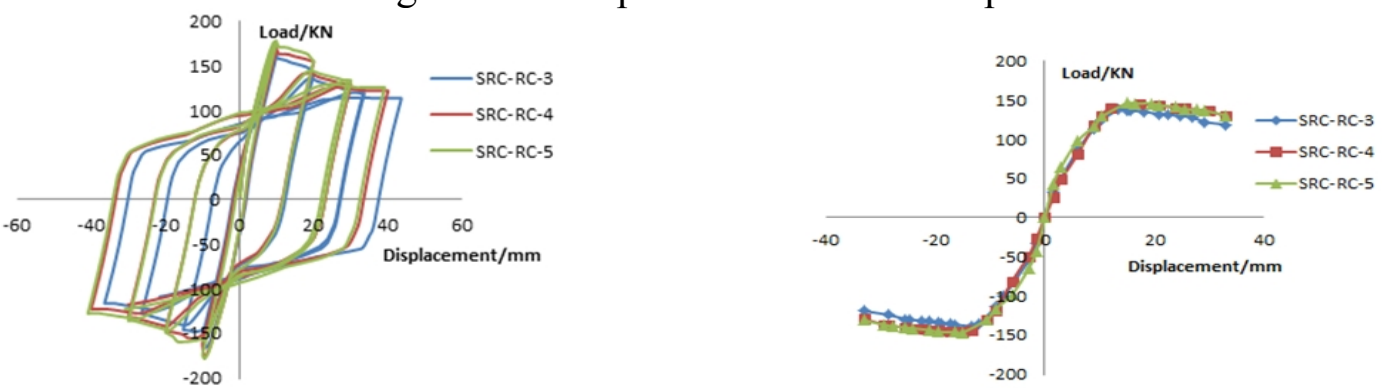

Fig.6.Hysteresis curves and skeleton curves comparison



SRC-RC-6 Maximum hysteresis loops



SRC-RC-7 Maximum hysteresis loops

Fig.7. The maximum hysteresis loops with different axial compression ratio 




SRC-RC-6 Skeleton curves

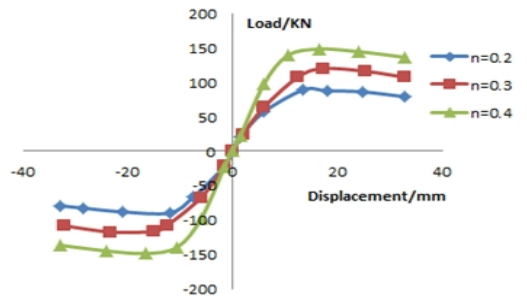

SRC-RC-7 Skeleton curves

Fig.8. Skeleton curves with different axial compression ratio

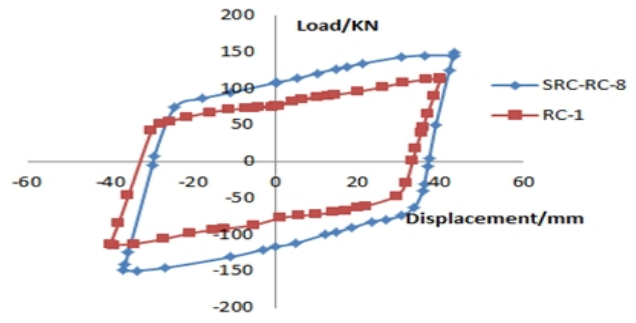

Fig.9. SRC-RC-8 and RC-1 column maximum hysteresis loop comparison

\section{Conclusions}

In this paper, the open source finite element software OpenSEES is used to apply static load and low cyclic load on SRC-RC transfer column do nonlinear finite element analysis. The main conclusions are as follows;

1) Under the premise of a reasonable set of material constitutive etc, the calculation results have higher credibility;

2) The effect of steel ratio on the bearing capacity and seismic performance of the SRC-RC transfer column is small;

3) The axial compression ratio of the hysteresis and the ultimate load of the SRC-RC converter are greatly affected. With the increase of the axial pressure ratio, the bearing capacity of the specimen is significantly increased.

4) Under the same conditions, the carrying capacity and seismic performance of the SRC-RC transfer column are better than RC column.

\section{Acknowledgments}

This work was financially supported by National Natural Science Foundation of China through Grant 51378240 .

\section{References}

[1] Kai Wu, Jianyang Xue, Hongtie Zhao, Danning Wang, Analysis of Seismic Performance of SRC-RC transfer column[J], World Earthquake Engineering, 2008,03:135-139

[2] Yanru Zhu, Zixiong Guo, Numerical simulation of SRC column under low-cyclic loading based on OpenSEES[J], Guangxi University (Natural Science), 2010,04: 555-559.

[3] Jianyang Xue, Kai Wu, Hongtie Zhao, Yongjian Shao, Xiaowei Jiang, Experimental Study on Seismic Performance of SRC-RC transfer columns[J], Building Structures, 2010,11: 102-110.

[4] Weiqiang Ma, Yun Zou, Qiang Wang, Hui Lin, Nonlinear numerical analysis of SRC-RC transfer columns[J], World Earthquake Engineering , 2013,02:156-160.

[5] Xuewei Chen, Zhe Lin, Structural Elastoplastic Analysis Program OpenSEES Principles and Examples, Beijing: China Building Industry Press, 2014 
[6] SCOTTB D, PARK R, PRIESTLEYM JN1Stress-strain behavior of concrete confined by overlapping hoops at low andhigh strain rates[J]1 ACI Stuctural Journa,1 1982, 79: 13-271 